Article

\title{
Development and Application of an Assessment Complement for Production System Audits Based on Data Quality, IT Infrastructure, and Sustainability
}

\author{
Aitor Goti ${ }^{1, *(\mathbb{D}}$, Alberto de la Calle ${ }^{1}\left(\mathbb{D}\right.$, María José Gil ${ }^{1}$, Ander Errasti ${ }^{2}$, Pedro R. D. Bom ${ }^{3}(\mathbb{D}$ and \\ Pablo García-Bringas ${ }^{1}$ (D) \\ 1 Faculty of Engineering, University of Deusto, 48014 Bilbao, Biscay, Spain; acalle@deusto.es (A.d.1.C.); \\ mariajose.gil@deusto.es (M.J.G.); pablo.garcia.bringas@deusto.es (P.G.-B.) \\ 2 Natra Chocolate Internacional, 20560 Oñati, Guipuzcoa, Spain; ander.errasti@natra.com \\ 3 Deusto Business School, University of Deusto, 48014 Bilbao, Biscay, Spain; pedro.bom@deusto.es \\ * Correspondence: aitor.goti@deusto.es; Tel.: +34-944-139-000
}

Received: 5 October 2018; Accepted: 6 December 2018; Published: 8 December 2018

\begin{abstract}
Some companies improve their production performance using manufacturing or operations

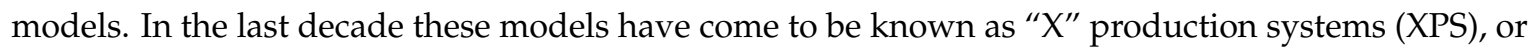
company-specific production systems. XPS systems have been oriented mainly to implement lean manufacturing and continuous improvement principles, but have shown little progress in terms of sustainability principles. The emergence of databases (DBs), big data, and business intelligence (BI) systems have enabled the creation of system panels to measure performance and manage business processes. These panels also allow assessment of the implementation of the principles, methods, and tools of the XPS. The effectiveness of these systems requires sufficient IT infrastructure and an acceptable quality of data, but the key performance indicator (KPI) panels of XPSs often lack consistent and acceptable data. In other cases, the IT infrastructure does not cover the needs of the personnel managing the operations, which limits the progress of XPSs. This paper documents the positive experience of one company in jointly auditing and improving data quality and IT infrastructure, which better aligned its XPS with sustainability objectives. It explores, using an empirical case study where the researchers were actively involved, the possibility of complementing the KPI panel system of XPS assessment systems with the principles of sustainability, data quality, and IT infrastructure. The paper describes the development and testing of an assessment tool based on those principles, and offers a number of results that may benefit similar small- and medium-sized companies (SMEs).
\end{abstract}

Keywords: manufacturing models; production systems; performance monitoring; industrial sustainability; industrial safety; data quality

\section{Introduction}

Lean manufacturing is a comprehensive philosophy for structuring, operating, controlling, managing, and continuously improving industrial processes [1]. This philosophy is employed in companies using a company-specific production system or " $X$ " production system (XPS) $[2,3]$, and describes a corporation-wide system that aims to improve and maintain a competitive operations system. Based mostly on the Toyota Production System (TPS) [4], XPSs have proliferated in the last decades. Many companies have developed more or less radical adaptations of this system to employ their business strategy in the manufacturing area; Daimler, for instance, implemented the Mercedes-Benz production system (MPS). In a very simplistic way, it can be stated that XPSs are ways of deploying lean manufacturing over an operations area or system. 
In order to increase their competitiveness, these XPSs prioritize and deploy improvement projects and routines linked to a series of principles (e.g., total quality, shortest lead-time). These principles are concepts that companies use to differentiate their work from others. Remarkably, however, most XPS principles seem to be misaligned with the principles of sustainability. In fact, while some companies are currently implementing approaches for aligning their business strategy with sustainability (e.g., References [5,6]), most companies do so only occasionally or not at all [7]. The present paper is motivated by this alignment, or lack thereof, which has been suggested to be "the next phase of business sustainability" [8].

Another question tackled in this research concerns the measurement and control of performance. Companies continuously measure the effectiveness of their actions not only with operations, but also with improvement projects that implement the principles, traditionally by means of queries to databases (DBs), pivot tables, etc. The last years have witnessed the development of big data and business intelligence (BI) systems to measure and support decision making, among other purposes. Given their success, many advanced countries are investing in big data and BI systems, taking advantage of the boom of the Industry 4.0 concept [9]. As in other areas, big data and BI systems are being applied to the management of operations [10]. Big data can be simply defined as a system for collecting and interpreting data sets that, due to their large volumes, cannot be conveniently captured, stored, managed, and analyzed with conventional tools [11]. Big data technologies are designed to extract useful information, quickly and inexpensively, from large volumes of data from different sources [12]. The aim is to use the "five Vs", i.e., volume, variety, velocity, veracity, and value, to support the decision-making process based on information managing [13].

Muntean [5] defines BI as an umbrella term for various business managing processes, based on well-informed decisions that should lead to high levels of performance in organizations. The author considers BI to be the art of gaining business advantages from data, covering areas like "business analysis", "enterprise reporting", and "performance management", offering them flexible, easily configurable, and dynamic sets of indicator panels. BI systems include applications, infrastructure, tools, and best practices that allow access to and analysis of information to improve the decision-making process and its effects [8]. Shukla and Dhir [14] define BI systems as a set of techniques and tools for processing and transforming, within seconds, large amounts of raw data into consistent, visual, and useful information for business analysis. Despite falling short of the original expectations, big data and BI systems are changing business and the industry [12,13].

In this new scenario, the emergence of DBs, big data and BI systems, among others, have facilitated the availability of indicator panels for any type for manager. As Muntean argues [5], business models are not viable without the support of technology and information systems. In the same vein, Hämäläinen and Inkinen [15] state that managers need much more merged and detailed information than before to make decisions in the area of sustainability. To this aim, they propose the use of DB and big data tools. Moreover, Can and Alatas [16] indicate that organizations can use big data to become smarter and more innovative. With indicators coming from DBs, big data, and/or BI systems, approaches towards improving the performance of a company and its sustainability can now be aligned in a relatively easy manner.

As Kai and Zhu [17] explain, however, both data quality and IT support are necessary conditions for the correct functioning of these systems. Otto, Wende, and Schmidt [18] reinforce the same idea, pointing out the need for systematically managing the quality of the data, and ensuring adequate IT structure, as key factors to enhance organizational anchorage towards data quality management. To summarize, insufficient data quality can lead a company into wrong decisions, whereas insufficient IT infrastructure limits the response capacity to the needs in the area of operations. This fact is known by practitioners who jointly audit data quality and IT infrastructure, as shown by Reference [19].

This paper reports the development and testing of an assessment complement for production system audits in a case study aimed at integrating the sustainability concepts into the XPS measurement systems. This assessment complement reviews the key elements so as to check: (a) how business 
strategy aligns with sustainability, and (b) how the data and infrastructure necessary to control the operations through an XPS are maintained. The assessment complement for production system audits was applied to the automotive component supplier Soraluce Hermanos, a cold stamping small- to medium-sized company (SME) specialized in the manufacture of high-quality, high-precision components for the automotive industry. The results show that this approach has been effective for the company, as it has outlined quick wins that have improved its results concerning economic and sustainability objectives. Finally, the paper emphasizes that more research is needed to assess the effectiveness of this approach to other companies.

Our paper therefore provides a management supporting tool aimed at promoting change in the natural evolution of businesses. The business culture still focuses predominantly on short-term financial performance, instead of integrating the broader contextual influences that could promote long-term success [20]. Changing this paradigm is notoriously complex, much more so if the systems of evaluation help perpetuate the model. The XPSs contribute to operational excellence in companies, which, as the term suggests, reinforces the traditional view of business management. Hence, our assessment tool complements the XPSs with sustainability criteria over the long term. On the other hand, incorporating a digital component into these systems opens an avenue to new vulnerabilities (i.e., "data leaks") and the possibility of unintended rebound effects [21], such as resistance by employees to the use of their individual productivity data. This paper is also meant to serve as a first step in extending the assessment complement to global supply chains. As the patterns of competition have shifted from the company level to entire supply chains [22], so should sustainability considerations cross the boundaries of the company. Although the assessment complement described in this paper was designed and implemented within a company, its concept can be extended and generalized to cross-company environments.

The paper is structured as follows. We first conduct a literature review in Section 2. Section 2.1 shows the evolution of the XPS and discusses the most common components found in this type of models. Section 2.2 then reviews how manufacturing models have dealt with sustainability concepts. Section 3 first formulates the research questions regarding the development of a big data, $\mathrm{BI}$, and sustainability audit system for complementing a XPS audit, and then shows how the research methodology was selected. Section 4 develops the auditing model, which is then tested in a real case in Section 5. Section 6 presents and discusses our results. Finally, Section 7 highlights the most relevant conclusions.

\section{Literature Review}

\subsection{Evolution of Manufacturing Models and Their Components}

Despite some definitional variations, several prominent authors (e.g., in References [3,23]) define manufacturing models as sets of managerial items designed to manage and improve manufacturing units, which are composed of six essential elements (see Figure 1: (1) values and vision; (2) principles; (3) tools, methods, and techniques; (4) business indicators; (5) organization; and (6) audit systems). Probably the best-known manufacturing model is the previously mentioned TPS or "House of Toyota", composed of the elements shown in Figure 2. 


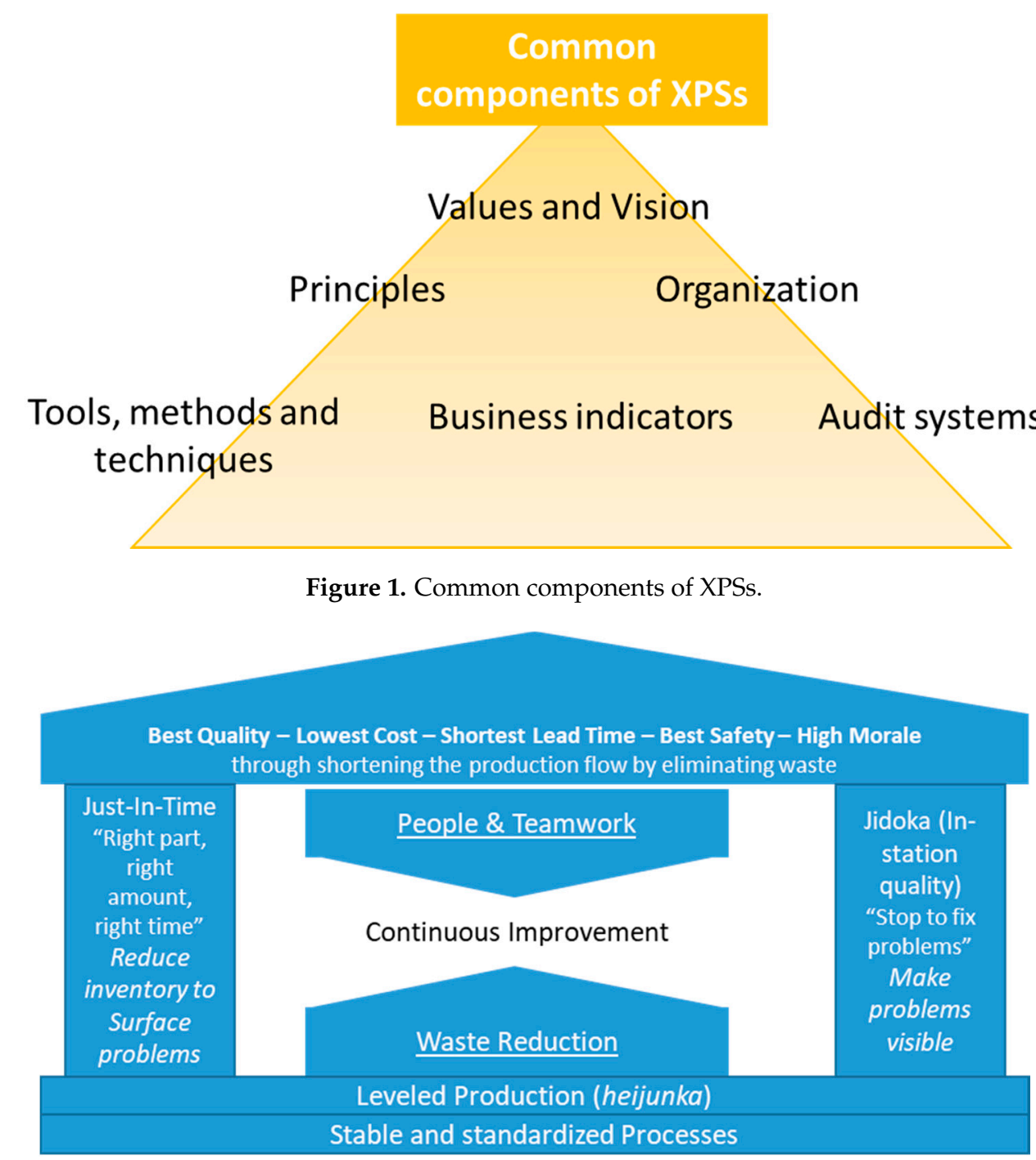

Figure 2. Elements of the Toyota Production System [24].

Soliman [25] describes TPS as a house, with all the components coherently implemented in order to hold up its structure (see Figure 2). In the most simplistic definition of TPS, all manufacturing activities are divided into either adding value or creating waste. The goal of TPS is then to maximize value by minimizing waste, applying the principles and elements shown in the house. Although TPS is probably the most famous XPS, there were other manufacturing models before, such as Taylorism (or Taylorismus) [26]. Figure 3 shows the chronological evolution of the most important XPSs. 


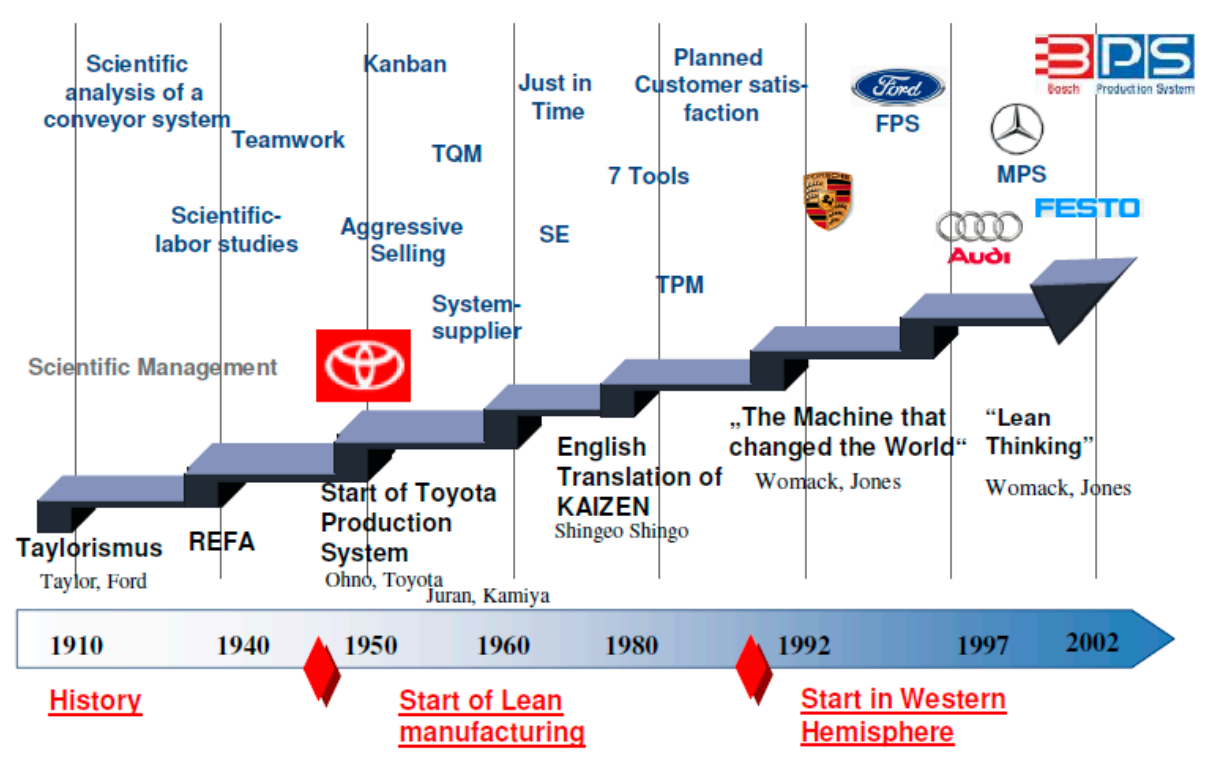

Figure 3. Evolution of XPSs [27].

Due to the success of TPS, and other models coming mainly from Japan, manufacturing models appeared massively in the industry during the 1980s. Currently, the great majority of relevant corporations in the industrial world have their manufacturing XPSs or "houses". These models have differences between them, as they rely on distinct principles, values, and tools. In an effort to understand the components of different XPSs, Netland [3] identifies 46 different principles, tools, and techniques (see Figure 4), a selection of which is used by each company to tailor its lean manufacturing model.

\begin{tabular}{|ll} 
& \\
& \\
Automation & \\
Clear communication & Order and material planning \\
Competitive benchmarking & Organizational design \\
Continuous Improvement/Kaizen & Overall Equipment Effectiveness (OEE) \\
Cross-functional training & Payment \\
Customer focus & Performance measurement \\
Design for manufacturing & PLC management \\
Employee involvement & Product Development \\
Enterprise resource Planning (ERP) & Profit-making \\
Flexibility & Pull system \\
Flow orientation & Quick change-over \\
Focused factory & Real-time response \\
Health, security and environment & Reduction of batch size \\
Heijunka & Sales \\
Innovation & Stability and robustness \\
Inventory management & Standardized work \\
Jidoka/Autonomation & Takt time \\
Just-in-Time & Teamwork \\
Leadership & Total quality \\
Lean supply chain & Transport on wheels \\
Maintenance & Value stream \\
New effective technology & Vision, culture and values \\
Optimized manning & Visualization \\
\hline Principles, TechniqueS and ToOls of the XPSS & Workplace management \\
\hline
\end{tabular}

Figure 4. Most common principles, tools, and techniques when developing Manufacturing or XPSs (adapted from [3]). 


\subsection{Evolution of the Link between XPSs and Sustainability}

The concept of sustainability has broadened over the last decades. It started by considering the classical dimensions of economic development, social development, and environmental protection [28], and evolved to the current representation of the 17 sustainability Development Goals (SDGs) agreed on by the United Nations (UN) at the Rio conference [29,30].

The adoption of lean and sustainability oriented operational practices has continuously grown. As Tasdemir and Gazo [31] indicate, common lean or XPS tools can provide significant contributions to sustainable development. The first XPS model with sustainability concerns was proposed by Piercy and Rich [32]. Specifically, this paper developed the first integrative stage-based lean and sustainable model, proving that lean operations (typically included in XPSs) meet a wide range of sustainability outcomes beyond mere environmental benefits (including supply monitoring, transparency, workforce treatment, and community engagement). Their paper specified the internal and external policies, procedures, tools, and strategies for implementing lean and sustainable operations management. The main drawback of this work, however, is the very concept of sustainability, which has since then evolved towards a different meaning. Their concept of sustainability did not include, for instance, any considerations regarding the SDGs.

This very same problem can be found in the literature linking XPSs to sustainability. Many of the studies focus exclusively on the environmental impact, with countless references to the topic (e.g., [33-36]). Other studies consider only the environmental, economic, and social components of sustainability (see the literature review by Tasdemir and Gazo [31], who analyze the intersection zone between lean manufacturing and sustainability). Again, the concept of sustainability in these studies, like in the remaining studies reviewed, does not include the actual view of the UN that is reflected in its 17 SDGs.

To summarize, companies demand more tools that allow them to embed sustainability into core business strategy [7]. More and more companies have their own XPS to transform their strategy into operational actions, most of them also working towards sustainability. The effectiveness and efficiency of these initiatives must be controlled through KPI panels and audit systems. Nevertheless, our review of the literature concluded that these audit systems do not consider the integrated evaluation of the performance of XPS and the 17 SGDs. This paper proposes a complementary tool for XPS audits that works in this direction, analyzing what the audited companies are doing towards the 17 SGDs while auditing the management of their operations.

\section{Research Method, Questions, and Limitations}

Researchers should choose, among the many methods available, the research strategy that best fits the research questions at hand [37]. Case studies can be used for research purposes such as exploration, theory building, theory testing, and theory extension/refinement. Action research (AR) can be seen as a variation of case research, in which the action researcher is not an independent observer [38]. AR is a phenomenological method that can be used to generate or to extend new theories [38-42]. The aim of AR is to contribute to academic research while also contributing to solving practitioners" problems, where the researcher(s) is/are actively involved in the process of change [37,39-45]. Operations management research often requires learning from application, and AR has become a more widely used approach for this discipline $[37,44]$. When evaluating the quality of the research, the research team carefully considered the criteria for AR. The research carried out via AR must demonstrate the practical relevance and usefulness of the outcomes in a particular organizational context $[39,41,43,46,47]$.

Open-wide methods such as, for instance, the transdisciplinary approach, in which researchers from various fields may join forces with non-research personnel [48], were first considered but later discarded. Most real life problems are, in fact, multifaceted, contextual, and holistic, and thus well-suited to transdisciplinary approaches [49]. However, the research pursued in this paper was considered specialized enough to deserve a more specific approach., Methods such as case study research [50], on the other hand, are very time-intensive, which conflicted with the time frame available 
for this research. AR was considered an appropriate technique for this study because it allows real life problems to be approached directly [48], within a reasonable time frame. Moreover, it provides a preliminary assessment of the direction of this investigation, which may pave the way for further examination using more complex (and time-consuming) methods in future research.

Critics of AR have spoken out "to brand it as consulting masquerading as research" [39], and have critiqued the lack of repeatability and generalizability due to its focus on solving a specific problem in a particular context. Due to this lack of generalizability, the conclusions extracted from this research can be considered valid only for this case, although they can provide some orientations for further research to validate theories using other research techniques. AR projects are specific to the context of action and, therefore, they do not aim to create universal knowledge [39]. Still, it is important to understand the implications of the findings outside the context of the AR study, so that they can be useful to other organizations $[39,43]$. The research must therefore demonstrate the practical relevance and usefulness of the outcomes in a particular organizational context [39,41,43,46,47]. In that sense, it is important that the final output be relevant, simple, and easy to use [51].

The AR presented in this paper focused on developing a solution to a complex industrial problem that was identified in Soraluce Hermanos. The main authors of the paper (and principal investigators of the research study) were employed in this company to tackle the challenge of jointly improving sustainability and business performance using the same resources. This approach produced an innovative and theory-grounded solution to a relevant practical problem, as it only required measuring the performance of a plant using criteria not usually considered by XPS audit systems.

The research questions formulated for the final output derive from balancing the marginal costs and benefits of conducting a more comprehensive and complex audit. Whereas a more complete audit can, in many occasions, lead to better results, the additional effort may not be worth it. We thus formulate the following research questions:

(1) Is it effective to perform a joint audit of the performance of a company considering its XPSs and how it manages its data quality and IT infrastructure?

(2) Is it beneficial to perform a joint audit of the performance of a company considering its XPSs and sustainability criteria (understanding sustainability in the context of the $17 \mathrm{SDGs}$ )?

If the answers to these questions are positive, then we can conclude that, at least in this specific context, it is worth complementing XPS systems with sustainability considerations, data quality, and IT infrastructure. In order to respond to them, the assessment complement for Production System audits and the case studied are presented in the following sections.

\section{Audit Complement for Production Systems Audits Based on Data Quality, IT Infrastructure, and Sustainability}

\subsection{XPS Audit Models: Context}

This section offers the necessary context to understand XPS audits. It shows how an XPS is visualized, in order to understand how an XPS audit is executed and presented. To this aim, Figures 5-7 show example screen caps of the performance of an XPS from the food sector [52]. Figure 5 shows the summary of the results of the audit. 


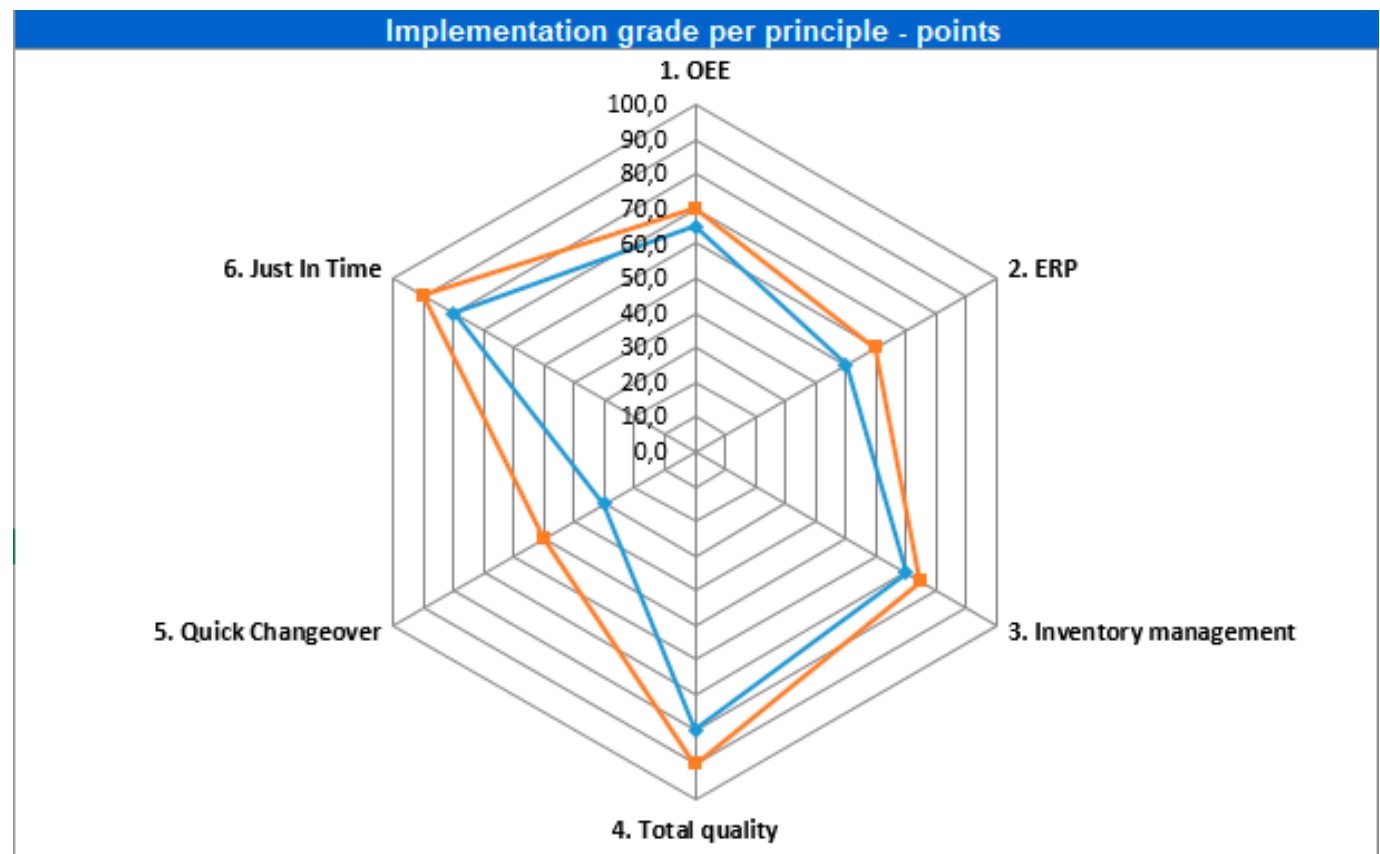

Figure 5. Summary radar of the audit results (result obtained in blue, objective for the next year in orange).

Production System - Reporting: Implementation level methods and tools

$\begin{array}{ll}\text { Factory: } & \text { Fxy } \\ \text { Date: } & \text { dd.mm.yyyy } \\ \text { Participants } & 0\end{array}$

\section{Principle: Total quality}

\subsubsection{Tool: HACCP}

Area of application: Production and production related areas

1. Are HACCP's systematically planned and executed timely?

Q. Is there a systematic method for the decision making process, when a HACCP is necessary?

Q. Are employees of all competence areas represented in the HACCP teams?

Q. Ar the type of the HACCP's and the area of application (e.g. components, assemblies, processes) defined?

Q. Are after the completion of HACCP certain measures planned?

Q. Are after definition of the measures consistently HACCP secondary evaluations accomplished?

Q. Are the measures of the HACCP's consequently and in time executed? Qualitative devaluation Total assessmen
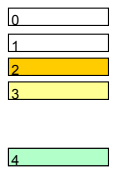

$=$ not planned

$=$ planned, not implemented

$=$ implemented in pilot area

$=$ implemented in several areas

(at least approx. $50 \%$ of the whole area of application)

$=$ completely implemented in the

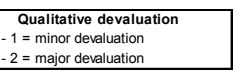

\section{$-1=$ minor devaluation
$-2=$ major devaluation}

Comments:

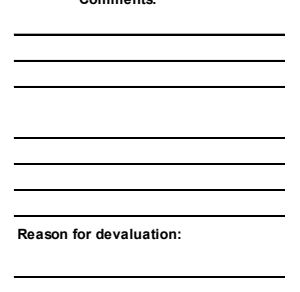

Comments:

4.1.4. Tool: BCR-IFS

Area of application: All manufacturing processes

1. Are we passing BCR-IFS audits successfully and in possitive less and less remarks for the last 5

\begin{tabular}{l|c|}
$\emptyset$-assessment $(0-4)$ & 0,0 \\
\cline { 2 - 2 } $\begin{array}{l}\text { Qualitative devaluation } \\
\text { Total assessment }\end{array}$ & 0,0 \\
\cline { 2 - 2 } &
\end{tabular}

Reason for devaluation:

Figure 6. Example of audit questions of the Total Quality principle of the XPS of a company of the Food Industry sector. 


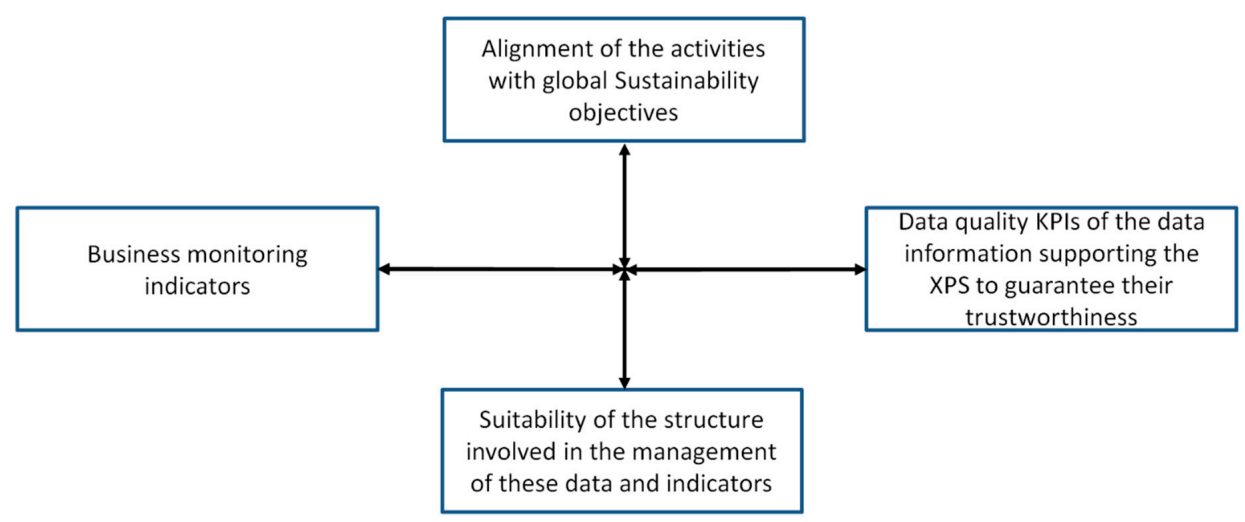

Figure 7. Proposal of the components of the XPS audit system integrating data quality, IT infrastructure, and sustainability.

As can be seen in Figure 5, it is typical in XPS audits not only to obtain a mark for each of the principles audited, but also to establish new objective values for the next year. These marks were obtained by interviewing plant directors using this type of XPS audit model, where both quantitative and qualitative data were gathered. Specifically, each of the components in the radar was divided into sub-concepts, as shown in Figure 6. In that Figure, we can see how the mark of the Total Quality principle was obtained by applying a questionnaire. In this specific case we can see that the mark was given by evaluating how the plant implements the HACCP (Hazard Analysis and Critical Control Points) tool, and how it deals with BRC (British Retail Consortium audit system) and IFS (International Featured Standard) audits, among others. (Note that it is not possible to provide more information regarding the XPS partially shown in Figure 6 due to confidentiality reasons.)

Regardless of the format and content of each checklist, quantifying the qualitative progression of multiple lean factors in each dimension is essential. A wide range of scoring methodologies can be used, such as simple Yes/No or Likert scales. In any case, it is necessary to obtain unique final audit values for any indicators shown in the radar of Figure 5.

Thus, XPSs inherit the values and the vision of the company, and ensure the application of their principles related to the manufacturing areas by the implementation of tools, methods, and techniques in an organized manner. Within the framework of these implementations, they control the performance of the system through a set of business indicators and a periodic review of the system as a whole through regular audits, such as the ones shown in Figures 5 and 6.

\subsection{Data Quality, IT Infrastructure, and Sustainability: an Assessment Complement for Production System Audits}

For both the operational KPIs and the XPS audit systems commented in the previous section, the support provided by the digitization of industry is surely fundamental. As presented in Section 2.1, companies develop their own system to coherently structure improvement programs. For this purpose, a body of coherent (a) values and vision, (b) principles, (c) tools, methods, and techniques, (e) business indicators, (f) organization, and (g) audit systems is defined by each company. The result of this research is a general complement for the XPSs of companies, reinforcing the way they manage and support their KPI and audit systems, which are essential for the satisfactory performance of any XPS. For such reinforcement, the literature review concluded that it is important to link business indicators to sustainability indicators. Also, the review concluded that data quality and IT infrastructure are key elements in correctly managing businesses correctly nowadays. Thus, the research proposed the control and audit system framework components shown in Figure 7.

The three components complementing the XPSs in this framework were based on references [53] for data quality and [54] for IT infrastructure, whereas it used the previously mentioned SDGs of the $\mathrm{UN}$ for the sustainability component. The specific concepts commented in the references analyzed 
for each of the components are as follows. For data quality Reference [53] shows as key concepts: (a) accuracy, (b) completeness, (c) uniqueness, (d) opportunity, (e) consistency, and (f) accessibility. Nevertheless, the attribute of processing-easiness was incorporated, as this component is needed when dealing with big data environments [55]. In fact, this type of environment is already quite frequent in the industry and this trend is expected to increase. Regarding infrastructure, the audit component was based on Reference [54] and remarks as key components: (a) availability, (b) infrastructure, (c) documentation, (d) management capabilities, and (e) personal expertise.

The incorporation of these two fields, data quality and IT infrastructure, into the assessment complement was undertaken against a background where data and information are increasingly important to companies. But the digital revolution also poses major threats, which may put at risk the viability and the future of companies, industries, and other human systems [56]. Note, however, that any vulnerabilities in our assessment complement are, by implication, those inherent to the information systems in their various stages: collection, storage, and analysis of data. All these concepts, along with the XPS items of each company, comprised the set of components to be audited, giving shape to the modified "House of XPS" shown in Figure 8.

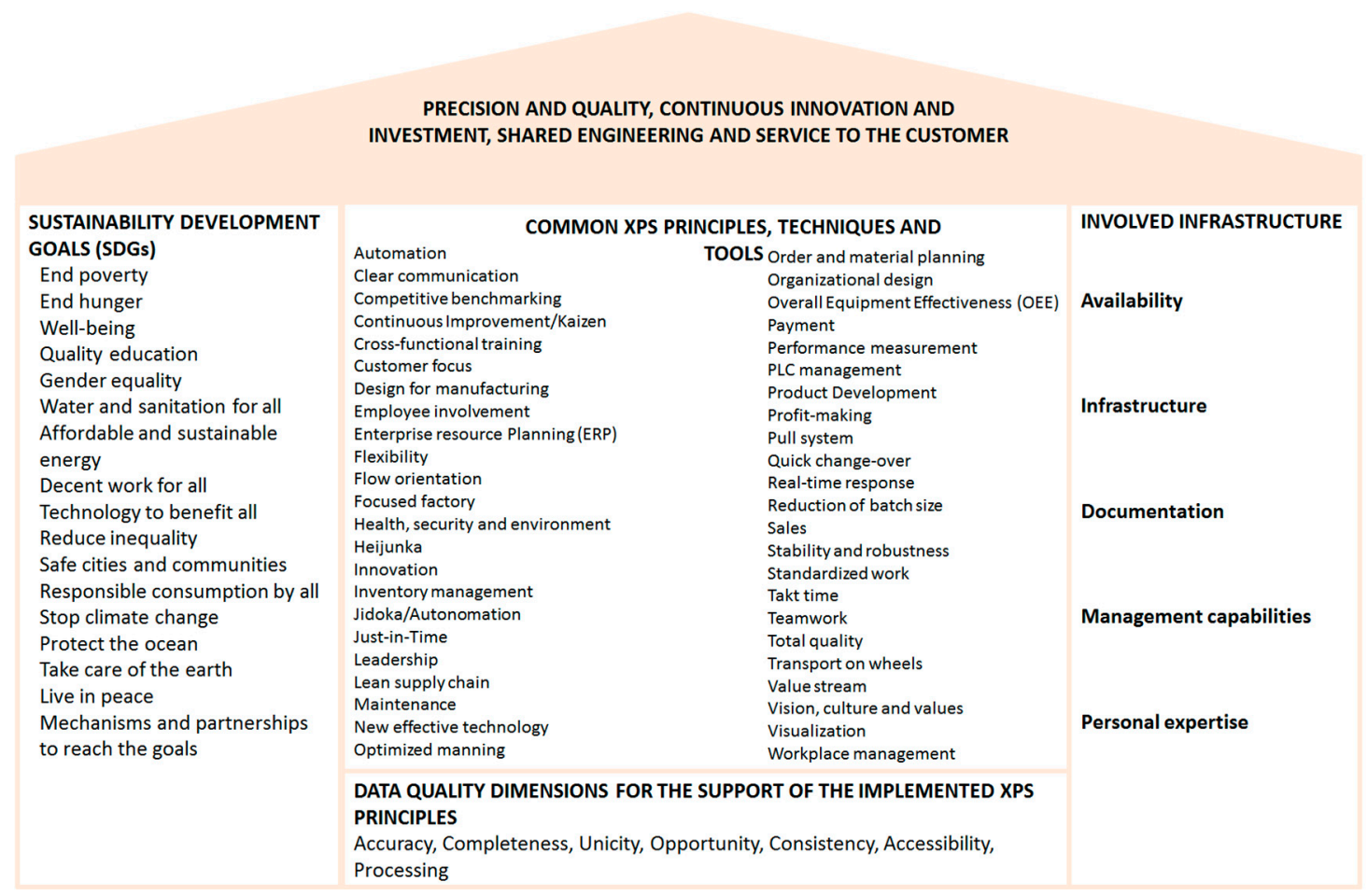

Figure 8. Auditable items of the sustainability, data quality, and IT infrastructure complement for XPSs, together with the main principles, tools, and techniques of these very same XPSs.

Maasouman [57] indicates that development assessment checklists are part of the design and customization of the development model for each organization. This author adds that the number of checklists, their content, type of questions, weighting and scoring methods, and assessment schedule should be customized accordingly. Thus, each company can select and/or create what questions to ask. Nevertheless, for this research, the questions related to data quality and IT infrastructure were made as generic as possible, based on the items collected from the frameworks of Data Quality attributes; see Wang and Strong [58], Bernstein and Dayal [59], and CIHI [60,61]. Similarly, Kim, Shin, Kim, and Lee [62] were taken as reference to generate the audit questions regarding infrastructure. Regarding sustainability, the 17 SDGs were reformulated as subjective questions to evaluate where the organization stands in each goal. For instance, for goal number 1 (no poverty), the question to be evaluated subjectively was "What did the company do in this last period to reduce poverty?" It is relevant 
to point out that, in some cases, it was necessary to apply an open interpretation of how actions and projects coming from XPSs can be linked to the SDGs. For instance, the SDG "protect the ocean" can be adapted to "project the river" if a company is not close to a seaside but lies adjacent to a river.

The questionnaire produced a multi-dimensional space of indicators regarding lean manufacturing, data quality, IT infrastructure, and sustainability. There will often be dependencies appearing between the different ratios in the various indicators (e.g., data quality and lean manufacturing). It was therefore essential to employ a single panel for all the audited items, which allowed visual correlations to be established between the ratios. Low marks in IT infrastructure, for instance, may lead to lower marks in data quality too. The questionnaire also allowed the company to reconsider the prioritization of actions. The audit results may indicate, for instance, very low marks in items previously considered to be of secondary importance, urging the company to move them up in the priority ladder. Take, as an example, the items "availability" and "documentation" under "involved infrastructure" (see Figure 8). Availability could, a priori, be considered to be more important than documentation, since the latter is an instrument to potentiate the former. If the obtained mark for documentation is much lower than that for availability, however, the company may find it optimal to prioritize actions in order to improve the quality of documentation.

As an example, Figure 9 shows a screenshot of the availability item of the audit, whereas the full assessment complement for production system audits can be found in the supplementary material section of the paper.

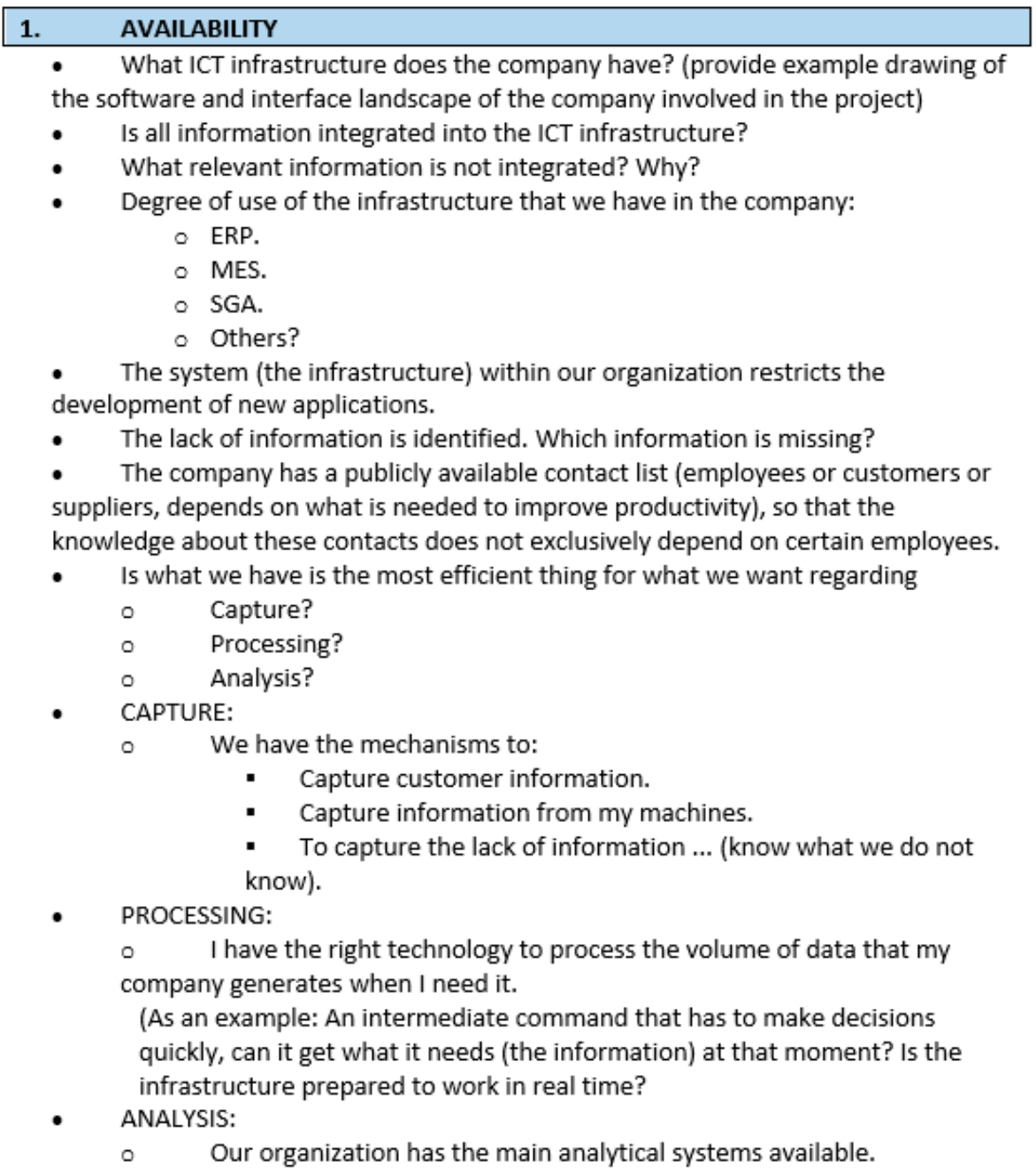

Figure 9. Audit questions and comments for the availability component (see the full complementary audit for XPSs in the supplementary material section). 
For the developed model it was proposed that respondents (usually directors of the different areas of the company) fill in the questionnaire, responding with a quantitative value. The value ranged between 0 and 100 as respectively worst and best possible scores. It was obligatory to add all possible observations justifying the score provided, as improvement remarks are often the basis of helpful audit conclusions. As the specific weight or importance of each question in the principle audited was different, the final score obtained was a result of the weighted average of the values obtained in each of the responses.

\section{Application}

The assessment complement for production system audits developed in the previous section was applied to the automotive component supplier Soraluce Hermanos, who employed the model with the support of IDS Industrial, a technological engineering company, and the University of Deusto. Its accomplishments rest on four master pillars: (a) precision and quality, (b) continuous innovation and investment, (c) shared engineering, and (d) service to the customer.

As shown in Figure 10, the principles that guide the management of its XPS are: (a) standardized work, (b) clear communication, (c) continuous improvement/kaizen, (d) total quality, (e) innovation, (f) inventory management, (g) visualization, (h) customer focus, (i) product development, (j) workplace management, (k) automation, (l) overall equipment effectiveness (OEE), (m) enterprise resource planning (ERP), (n) maintenance, (o) performance measurement, and (p) PLC management.

\begin{tabular}{|c|c|c|c|}
\hline & \multicolumn{2}{|c|}{$\begin{array}{l}\text { VALUES AND VISION: PRECISION AND QUALITY, CONTINUOUS } \\
\text { INNOVATION AND INVESTMENT, SHARED ENGINEERING AND SERVICE } \\
\text { TO THE CUSTOMER }\end{array}$} & \\
\hline \multirow[t]{2}{*}{$\begin{array}{l}\text { SUSTAINABILITY DEVELOPMENT } \\
\text { GOALS (SDGs) } \\
\text { End poverty } \\
\text { End hunger } \\
\text { Well-being } \\
\text { Quality education } \\
\text { Gender equality } \\
\text { Water and sanitation for all } \\
\text { Affordable and sustainable } \\
\text { energy } \\
\text { Decent work for all } \\
\text { Technology to benefit all } \\
\text { Reduce inequality } \\
\text { Safe cities and communities } \\
\text { Responsible consumption by all } \\
\text { Stop climate change } \\
\text { Protect the ocean } \\
\text { Take care of the earth } \\
\text { Live in peace } \\
\text { Mechanisms and partnerships } \\
\text { to reach the goals }\end{array}$} & $\begin{array}{l}\quad \text { PRINCIPLES OF TH } \\
\text { Automation } \\
\text { Clear communication } \\
\text { Competitive benchmarking } \\
\text { Continuous Improvement/Kaizen } \\
\text { Cross-functional training } \\
\text { Customer focus } \\
\text { Design for manufacturing } \\
\text { Employee involvement } \\
\text { Enterprise resource Planning (ERP) } \\
\text { Flexibility } \\
\text { Flow orientation } \\
\text { Focused factory } \\
\text { Health, security and environment } \\
\text { Heijunka } \\
\text { Innovation } \\
\text { Inventory management } \\
\text { Jidoka/Autonomation } \\
\text { Just-in-Time } \\
\text { Leadership } \\
\text { Lean supply chain } \\
\text { Maintenance } \\
\text { New effective technology } \\
\text { Optimized manning }\end{array}$ & $\begin{array}{l}\text { KPS OF SORALUCE HERMANOS } \\
\text { Order and material planning } \\
\text { Organizational design } \\
\text { Overall Equipment Effectiveness (OEE) } \\
\text { Payment } \\
\text { Performance measurement } \\
\text { PLC management } \\
\text { Product Development } \\
\text { Profit-making } \\
\text { Pull system } \\
\text { Quick change-over } \\
\text { Real-time response } \\
\text { Reduction of batch size } \\
\text { Sales } \\
\text { Stability and robustness } \\
\text { Standardized work } \\
\text { Takt time } \\
\text { Teamwork } \\
\text { Total quality } \\
\text { Transport on wheels } \\
\text { Value stream } \\
\text { Vision, culture and values } \\
\text { Visualization } \\
\text { Workplace management }\end{array}$ & INVOLVED INFRASTRUCTURE \\
\hline & \multicolumn{2}{|c|}{$\begin{array}{l}\text { DATA QUALITY DIMENSIONS FOR THE SUPPORT OF THE IMPLEMENTED XPS } \\
\text { PRINCIPLES } \\
\text { Accuracy, Completeness, Unicity, Opportunity, Consistency, Accessibility, } \\
\text { Processing }\end{array}$} & \\
\hline
\end{tabular}

Figure 10. Adaptation of the audit model developed to XPS of Soraluce Hermanos.

The board of directors responded to the questions of the audit, as is usual with the traditional principles of XPSs. Using this information, the set of 3 radar charts shown in Figure 11 was generated. These radars complement the usual XPS control panels and offer a quick view of the results of the audit systems. 


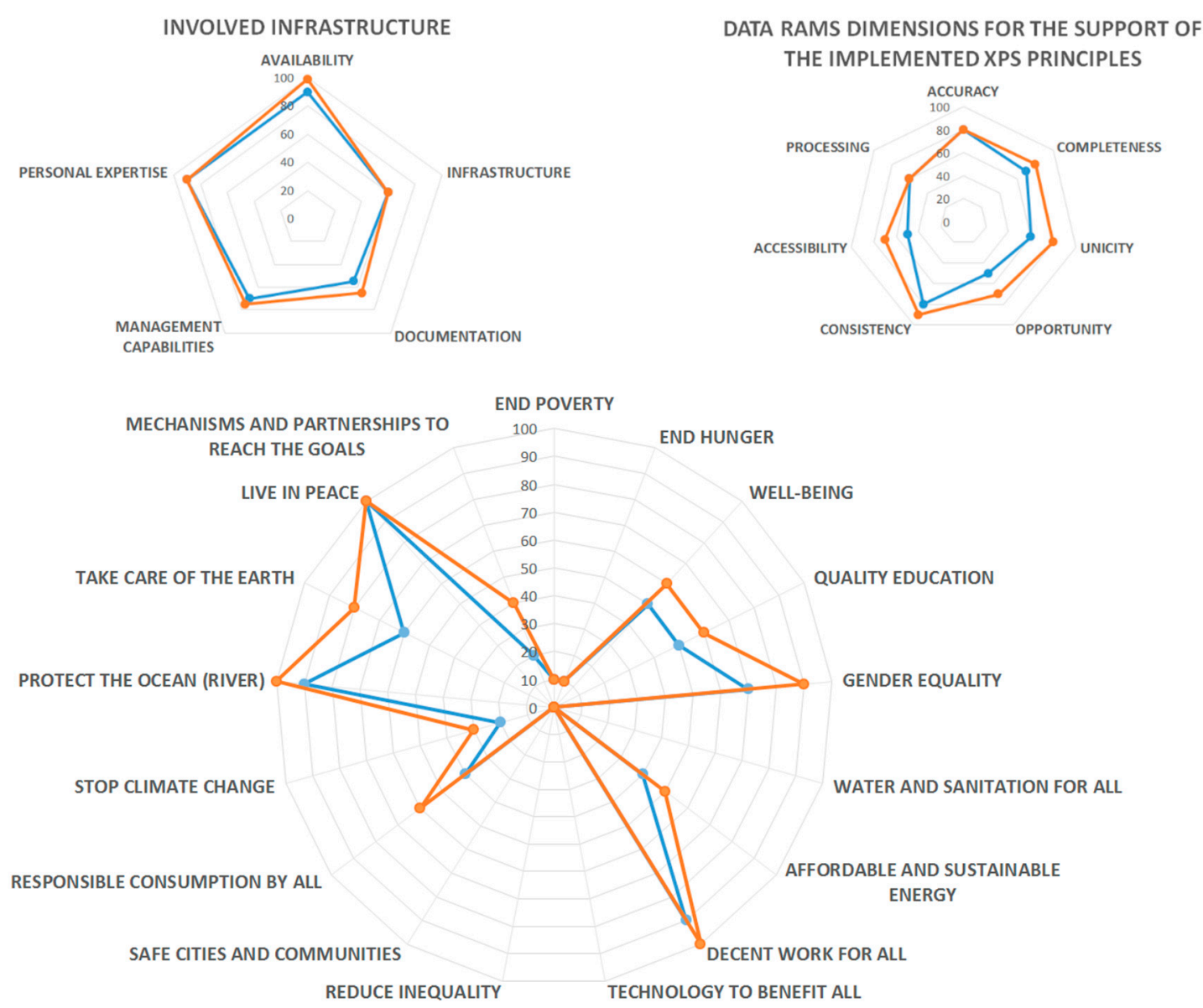

Figure 11. Visual representation of the results of the complementary audit model for XPSs obtained by Soraluce Hermanos (results regarding the XPS were not included due to confidentiality reasons).

\section{Results and Discussion}

\subsection{Results}

The application of the assessment complement for production system audits to the case of Solaruce Hermanos allowed both the company and the research team to obtain a set of results, which are discussed in the following paragraphs.

As with most performance audits, the main added value of the audit to Soraluce Hermanos was, more than the scores, the set of problems and opportunities detected (e.g., coordination and prioritization of actions). In this case the work was useful to visualize priorities, align efforts towards common goals, and link sustainability objectives to business objectives easily. For example, regarding the link between sustainability and business objectives via big data and BI tools, the company detected one weakness concerning data analysis (see the eighth question in Figure 9). They argued that they had efficient tools for gathering and processing, but not analyzing, the data. As a result, some BI panels or cubes were implemented, one of them aligned with SDG number 7: Affordable and Clean Energy. The initiative tackled the items of the XPS audit tool marked in red in Figure 12. 


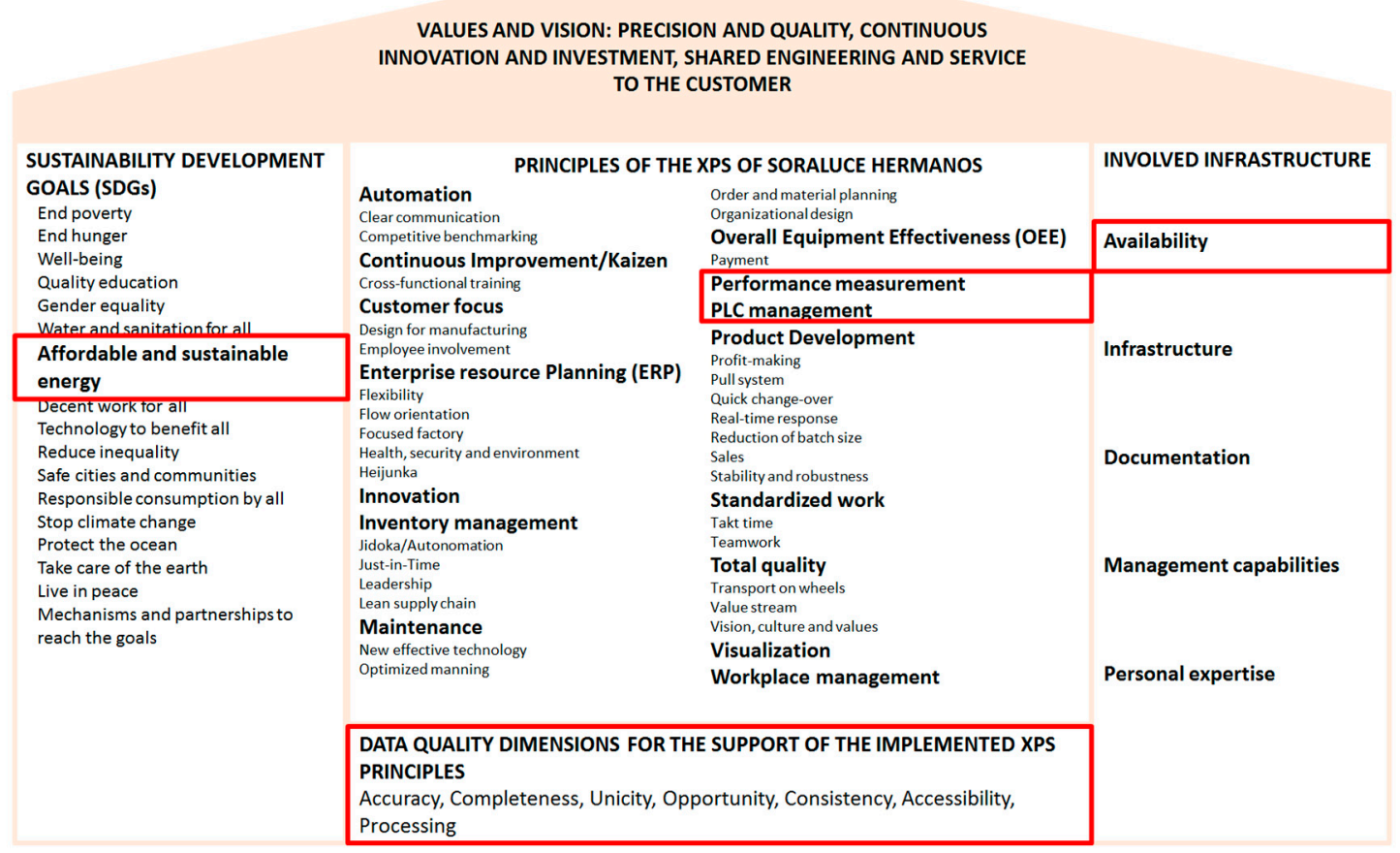

Figure 12. Items of the XPS audit used to detect and follow up the improvement action combining business, sustainability, and IT infrastructure components.

The existing IT infrastructure allowed identification of periods of time to run some equipment so that the energy consumed was cleaner and cheaper. Overall, the process was as cost-effective as before taking the action. This change implied extra costs, both in terms of the coordination difficulty in scheduling the resources, which introduced some time restrictions, and the resulting higher labor costs, but enhanced sustainability.

Both the company and the research team highlighted the importance of monitoring the interannual trends in the obtained audit results. This means that the results of the audit are to be measured and improved over the medium and long term, not merely in the first year of implementation. Regarding this orientation towards continuous improvement, the case provides an interesting example in the area of sustainability. In fact, the scores corresponding to the 17 SDGs were rather low, suggesting that there is significant room to improve.

Similarly, but not so evidently, to face this type of audit for the first time was an eye-opener for the direction of Soraluce Hermanos, in that some questions served to change the status of the company from "unconsciously incompetent" to "consciously incompetent" in situations where quick gains were implementable. The first question regarding availability, for example, which involved checking whether the company had a drawing of the software and interface landscape, a visual inventory of the maintenance requirements regarding IT, triggered an action towards having a visual inventory drawing. This action permits an easy global view on the scope of IT tasks, and eases the definitions of roles and responsibilities among team members. Visiting the developed drawing periodically also allows checking if workload among IT members is balanced, if every service is properly covered, etc.

\subsection{Discussion}

This section revisits the research questions formulated when presenting the AR methodology applied to this research (Section 3):

(1) Is it effective to perform a joint audit of the performance of a company considering its XPSs and how it manages its data quality and IT infrastructure? 
(2) Is it beneficial to perform a joint audit of the performance of a company considering its XPSs and sustainability criteria (understanding sustainability in the context of the $17 \mathrm{SDGs}$ )?

In both cases, the literature review and the case of Soraluce Hermanos demonstrate the practical relevance and usefulness of complementing XPS audits with audit questions. It allows: (a) improvement of the management of the data quality related to lean manufacturing and the IT infrastructure that maintains it; and (b) verification of whether the business objectives are aligned with sustainability objectives. The literature review justified the relevance of this research initiative, concluding that, up to the time of writing, no XPS existing audit model had jointly audited lean manufacturing and sustainability principles (within the scope of the 17 SDGs). In addition, and based on the literature, it has been considered necessary to complement the XPS audit models with data quality and IT infrastructure questions.

Finally, and addressing the research questions previously formulated, the case study outlined clear guidelines on how to improve sustainability together with plant performance. Additionally, it proposed improvements on where and how to channel the efforts regarding data quality and IT infrastructure. Thus, the resulting audit model sketches a more complete set of improvement suggestions when compared to an audit model without sustainability, data quality, and IT infrastructure. This assessment complement tool, although designed at the level of the organization, can be generalized and extended to the inter-organization level-for example, to entire supply chains. Regarding the limitations of this research, it is worth reiterating that the repeatability and generalizability of the conclusions obtained via $A R$ are limited to this case.

\section{Conclusions}

This paper highlights the ability of a firm trying to jointly audit and improve data quality, along with IT infrastructure, to better align its XPS with sustainability. The study presents the development and application of an assessment complement for XPS audits based on data quality, IT infrastructure, and sustainability, applied to an industrial case. The paper identified the most relevant elements of XPSs and reviews the literature, linking XPSs with sustainability, data quality, and IT infrastructure. The literature review concluded that it is relevant to develop a complementary audit model for XPS audits to guarantee the correctness of the data quality for the area of operations, and to check whether and how business objectives are linked to sustainability objectives. Also, the review found that existing XPS models do not incorporate sustainability principles as defined by the 17 SDGs.

The developed model was tested in an industrial SME. The company detected with this extended audit several improvement areas that would otherwise have gone unnoticed. The company has therefore made the decision to periodically review the status of its XPS based on this new approach. The results obtained in the case of Soraluce Hermanos have aroused the interest of other companies. The extension of this approach to other companies will allow consolidation of the results of the present study. These future applications, perhaps under different methodologies and frameworks, such as the Case Study research [50], will permit verification of whether the conclusions obtained in this research can somehow be generalized to other contexts.

Author Contributions: The six authors all participated in this manuscript. A.G. made the writing, conceptualization and investigation; A.d.l.C. and M.J.G. the conceptualization and investigation; A.E. the writing and the funding acquisition; and finally P.R.D.B. and P.G.-B. the writing.

Funding: This research was funded by University-Company call of the Basque Government, project number UE2016-10.

Acknowledgments: We would like to thank Olatz Soraluce and the full board of Directors of Soraluce Hermanos, and Iñaki Roman from IDS-Industrial for the opportunity given.

Conflicts of Interest: The authors declare no conflict of interest. 


\section{References}

1. Detty, R.B.; Yingling, J.C. Quantifying benefits of conversion to lean manufacturing with discrete event simulation: A case study. Int. J. Prod. Res. 2000, 38, 429-445. [CrossRef]

2. Netland, T. Can Production Systems give competitive advantage?-A case study of the Volvo Production System. In Proceedings of the 2010 EurOMA Conference, Porto, Portugal, 6-9 June 2010.

3. Netland, T. Exploring the phenomenon of company-specific production systems: One-best-way or own-best-way? Int. J. Prod. Res. 2013, 51, 1084-1097. [CrossRef]

4. Ohno, T. Toyota Production System: Beyond Large-Scale Production; Productivity Press: New York, NY, USA, 1988; ISBN 9780915299140.

5. Muntean, M. Business intelligence issues for sustainability projects. Sustainability 2018, 10, 335. [CrossRef]

6. Ranganathan, J. Big Business and Sustainability: The Missing Links. Guardian Sustainable Business. The Guardian. 2013. Available online: https:/ / www.theguardian.com/sustainable-business/tools-strategieschallenges-missing-links (accessed on 25 July 2018).

7. The Guardian. Aligning Sustainability and Profit: What Are the Barriers? Available online: https://www. theguardian.com/sustainable-business/aligning-sustainability-profit-barriers-companies (accessed on 26 July 2018).

8. Hoffman, A.J. The Next Phase of Business Sustainability. Available online: https://ssir.org/articles/entry / the_next_phase_of_business_sustainability (accessed on 26 July 2018).

9. Hernández, J.M. Is Spain trusting Industry 4.0? (Editor note). DYNA 2017, 92, 125.

10. Goti, A.; De la Calle, A.; Gil, M.J.; Errasti, A.; Uradnicek, J. Aplicación de un sistema Business Intelligence en un contexto Big Data de una empresa industrial alimentaria. DYNA 2017, 92, 347-353. [CrossRef]

11. Gallego Gomez, C.; De Pablos Heredero, C. Customer Relationship Management (CRM) and Big Data: A conceptual approximation and its influence on the value of data applied to the sales strategy. DYNA 2017, 92, 274-279. [CrossRef]

12. Han, H.; Yonggang, W.; Tat-Seng, C.; Xuelong, L. Toward Scalable Systems for Big Data Analytics: A Technology Tutorial. IEEE Access 2014, 2, 652-687. [CrossRef]

13. White, M. Digital workplaces: Vision and reality. Bus. Inf. Rev. 2012, 29, 205-214. [CrossRef]

14. Shukla, A.; Dhir, S. Tools for data visualization in Business Intelligence: Case Study using the tool Qlikview. In Information Systems Design and Intelligent Applications. Advances in Intelligent Systems and Computing; Satapathy, S., Mandal, J., Udgata, S., Bhateja, V., Eds.; Springer: New Delhi, India, 2016; pp. 319-326. ISBN 9788132227502.

15. Hämäläinen, E.; Inkinen, T. How to Generate Economic and Sustainability Reports from Big Data? Qualifications of Process Industry. Processes 2017, 5, 64. [CrossRef]

16. Can, U.; Alatas, B. Big Social Network Data and Sustainable Economic Development. Sustainability 2017, 9 , 2027. [CrossRef]

17. Cai, L.; Zhu, Y. The Challenges of Data Quality and Data Quality Assessment in the Big Data Era. Data Sci. J. 2015, 14, 2. [CrossRef]

18. Otto, B.; Wende, K.; Schmidt, A.; Osl, P. Towards a Framework for Corporate Data Quality Management. In Proceedings of the ACIS 2007, Toowoomba, Australia, 5-7 December 2007.

19. LLoyds Consulting Group Data Audit Framework Template. Available online: https://www.lloyds. com/market-resources/regulatory/ \{\}/ \{\}/media/b0680d72c58946afb2d38ac4662b563f.doc (accessed on 30 October 2018).

20. Brenner, B. Transformative Sustainable Business Models in the Light of the Digital Imperative-A Global Business Economics Perspective. Sustainability 2018, 10, 4428. [CrossRef]

21. Scholz, R.-W. Sustainable digital environments: What major challenges is humankind facing? Sustainability 2016, 8, 726. [CrossRef]

22. Roussel, J.-S. The strategic supply chain advantage: Treating supply chain as a strategic asset. In Proceedings of the SAPICS 35th Annual Conference and Exhibition, Sun City, South Africa, 2-4 June 2013.

23. Netland, T.; Ferdows, K.; Sanchez, E. How Company-Specific Production Systems Affect Plant Performance: The S-Curve Theory. Prod. Oper. Manag. 2015, 24, 362-364. [CrossRef]

24. Liker, J.K. The Toyota Way in Services: The Case of Lean Product Development. New book on Lean Product-Process Development View project. Acad. Manag. Perspect. 2006, 20, 5-20. [CrossRef] 
25. Soliman, M.H.A. What Toyota Production System Is Really About? Unpublished. 2015.

26. Roser, C. "Faster, Better, Cheaper" in the History of Manufacturing: From the Stone Age to Lean Manufacturing and Beyond, 1st ed.; CRC Press: Boca Raton, FL, USA, 2016; ISBN 9781315350912.

27. Greissinger, K. Lean Manufacturing and Ergonomic Workcell Design. Available online: https://www. slideshare.net/CMAFH/lean-manufacturing-and-ergonomic-workcell-design (accessed on 6 November 2017).

28. Social Watch. What Is Sustainable Development? The Evolution of the Idea, Social Watch. Available online: http:/ / www.socialwatch.org/node/12477 (accessed on 22 August 2018).

29. European Commission. The Sustainable Development Goals-European Commission. Available online: https: / / ec.europa.eu/europeaid/policies/sustainable-development-goals_en (accessed on 25 July 2018).

30. United Nations. Sustainable Development Goals: 17 Goals to Transform Our World. Available online: https:/ / www.un.org/sustainabledevelopment/ (accessed on 25 July 2018).

31. Tasdemir, C.; Gazo, R. A Systematic Literature Review for Better Understanding of Lean Driven Sustainability. Sustainability 2018, 10, 2544. [CrossRef]

32. Piercy, N.; Rich, N. The relationship between lean operations and sustainable operations. Int. J. Oper. Prod. Manag. 2015, 35, 282-315. [CrossRef]

33. De La Heras Garcia Vinuela, A.; Aguayo Gonzalez, F.; Cordoba Roldan, A. Proposal of a work framework for the evaluation of the sustainability of products from the paradigm of the circular economy based on Industry 4.0 (part 1). DYNA 2018, 93, 360-364. [CrossRef]

34. Morcillo Bellido, J.; Prida Romero, B.; Martinez Belotto, J. Sustainability: How do energy service companies (ESE) contribute? DYNA 2018, 93, 385-390. [CrossRef]

35. Simboli, A.; Taddeo, R.; Morgante, A. Value and Wastes in Manufacturing. An Overview and a New Perspective Based on Eco-Efficiency. Adm. Sci. 2015, 4, 173-191. [CrossRef]

36. Tsai, W.-H.; Lai, S.-Y.; Tsai, W.-H.; Lai, S.-Y. Green Production Planning and Control Model with ABC under Industry 4.0 for the Paper Industry. Sustainability 2018, 10, 2932. [CrossRef]

37. Rowley, J. Using case studies in research. Manag. Res. News 2002, 25, 16-27. [CrossRef]

38. Westbrook, R. Action research: A new paradigm for research in production and operations management. Int. J. Oper. Prod. Manag. 1995, 15, 6-20. [CrossRef]

39. Coughlan, P.; Coghlan, D. Action research for operations management. Int. J. Oper. Prod. Manag. 2002, 22, 220-240. [CrossRef]

40. Zuber-Skerritt, O. A model for designing action learning and action research programs. Learn. Organ. 2002, 9, 143-149. [CrossRef]

41. Susman, G.I.; Evered, R.D. An Assessment of the Scientific Merits of Action Research. Adm. Sci. Q. 1978, 23, 582. [CrossRef]

42. Perry, C.; Zuber-Skerritt, O. Action research in graduate management research programs. High. Educ. 1992, 23, 195-208. [CrossRef]

43. Eden, C.; Huxham, C. Action Research for Management Research. Br. J. Manag. 1996, 7, 75-86. [CrossRef]

44. Rae, D. Qualitative Methods in Management Research, 2nd edition, Evert Gummesson, Sage, London, 2000, 240 pp, ISBN 0-7619-2013-7,?50.00. Strateg. Chang. 2001, 10, 181-182. [CrossRef]

45. Coghlan, D.; Brannick, T. Doing Action Research in Your Own Organization; SAGE: Thousand Oaks, CA, USA, 2010; ISBN 1848602162.

46. Coughlan, P.; Coghlan, D. Action Research. In Researching Operations Management; Karlsson, C., Ed.; Routledge: New York, NY, USA, 2009; pp. 236-264.

47. Kasanen, E.; Lukka, K.; Siitonen, A. The constructive approach in management accounting research. J. Manag. Account. Res. 1993, 5, 243-264.

48. Habermann, B.; Misganaw, B.; Peloschek, F.; Dessalegn, Y.; Gselassie, Y. Inter- and Transdisciplinary Research Methods in Rural Transformation Case Studies in Northern Ethiopia; Centre for Development Research, University of Natural Resources and Life Sciences, BOKU: Vienna, Austria, 2013.

49. Editorial Comment. Action research or transdisciplinary research? TD J. Transdiscipl. Res. South. Afr. 2010, 6, vii-viii. Available online: https://td-sa.net/index.php/td/article/viewFile/267/244 (accessed on 15 August 2018).

50. Yin, R.K. Case Study Research: Design and Methods, 4th ed.; SAGE: Thousand Oaks, CA, USA, 2009. 
51. Lanning, H. Planning and Implementing Change in Organisations: A Construct for Managing Chance Projects; Helsinki University of Technology: Espoo, Finland, 2001.

52. Errasti, A.; Goti, A.; Natra, S.A. PTQ-12-05653 Torres Quevedo reseach project report-Development and implementation of the industrial management model: Natra Production \& Quality System. 2016.

53. DAMA. The Six Primary Dimensions for Data Quality Assessment; DAMA International: London, UK, 2013.

54. Anand, A. The Effects of IT Capabilities on Firm Performance-Evidence from the Healthcare Industry. Ph.D. Thesis, School of Information Systems \& Technology, University of Wollongong, Wollongong, Australia, 2013.

55. Mcafee, A.; Brynjolfsson, E. HBR.ORG Spotlight on Big Data Big Data: The Management Revolution. Harv. Bus. Rev. 2012, October, 3-9. Available online: https:/ /hbr.org/2012/10/big-data-the-managementrevolution (accessed on 15 August 2018).

56. Scholz, R.-W. Digital threat and vulnerability management: The SVIDT method. Sustainability 2017, 9, 554. [CrossRef]

57. Maasouman, M.A. Development of Lean Maturity Model for Operational Level Planning. Master's Thesis, Concordia University, Montreal, QC, Canada, 2014.

58. Wang, R.Y.; Strong, D.M. Beyond Accuracy: What Data Quality Means to Data Consumers. Source J. Manag. Inf. Syst. 1996, 12, 5-33. [CrossRef]

59. Bernstein, P.A.; Dayal, U. An Overview of Repository Technology. In Proceedings of the 20th VLDB Conference, Santiago, Chile, 12-15 September 1994; pp. 705-713.

60. CIHI's Information Quality Framework. 2017. Available online: https://www.cihi.ca/sites/default/files/ document/iqf-summary-july-26-2017-en-web_0.pdf (accessed on 15 August 2018).

61. The CIHI Data Quality Framework. 2009. Available online: https://www.cihi.ca/en/data_quality_ framework_2009_en.pdf (accessed on 15 August 2018).

62. Kim, G.; Shin, B.; Kim, K.K.; Lee, H.G. IT Capabilities, Process-Oriented Dynamic Capabilities, and Firm Financial Performance. J. Assoc. Inf. Syst. 2011, 12, 487. [CrossRef]

(C) 2018 by the authors. Licensee MDPI, Basel, Switzerland. This article is an open access article distributed under the terms and conditions of the Creative Commons Attribution (CC BY) license (http:/ / creativecommons.org/licenses/by/4.0/). 